\title{
O COTIDIANO DAS AULAS DE EDUCAÇÃO FÍSICA NA EDUCAÇÃO INFANTIL: OS BRINQUEDOS EM CENA
}

João Augusto Galvão Rosa Costa ${ }^{(*)}$ Dinah Vasconcellos Terra ${ }^{(*)}$

Podemos não lembrar das experiências, mas a Educação Infantil é uma etapa que vivenciamos no processo de escolarização. Nesse contexto, as rotinas da sala de aula, o recreio, a entrada, a saída da escola, as atividades direcionadas pelos professores, os eventos pedagógicos, a convivência com sujeitos de outras faixas etárias começam a ser percebidas e compreendidas pelas crianças.

Quando pensamos em rotina, corroboramos com o entendimento de Barbosa (2008), visto que rotina seria uma categoria pedagógica organizada pelos profissionais da educação infantil que estabelecem estratégias, pensando no emprego das relações com o tempo e espaço escolar. Nesse sentido, pensar a rotina e o cotidiano são fundamentais na constituição desse trabalho.

O cotidiano como uma categoria de análise fornece sentidos, significados, fontes, percepções, sensações, emoções, discussões e reflexões. Segundo Certeau (2005),“o cotidiano está ligado há aquilo que nos prende intimamente, a partir do interior” (p. 31). Logo, trazer à tona as questões vivenciadas no processo de ensino, seja nos espaços formais ou não formais, contribuem para a ampliação e construção das práticas pedagógicas.

Compreendemos que a Educação Infantil é a primeira etapa da educação básica e que a Educação Física, integrada à proposta pedagógica da escola, é um componente curricular obrigatório na educação básica pautada na Lei de Diretrizes e Bases LDBEN 9.394/96. (BRASIL, 1996). Assim, deve fazer parte do trabalho integrado ao currículo escolar, dialogando com as questões que as crianças apresentam durante as aulas, bem como reflexões perante as práticas pedagógicas desenvolvidas, novos olhares e metodologias que oportunizem diversificadas intervenções.

Nesse sentido, partimos do cotidiano das aulas de Educação Física na E.M. Cora Coralina, localizada no bairro Gramacho (Duque de Caxias). Nessa instituição, a Educação Infantil, possui

\footnotetext{
${ }^{(*)}$ Especialista em Educação Física escolar pela (UFF), Especialista em Docência da Educação Básica pelo Colégio Pedro II. Professor de Educação Física da Rede Municipal de Duque de Caxias.E-mail: galvao.uff@hotmail.com.

${ }^{(* *)}$ Doutora em Ciências da Educação pela Universidade de Barcelona (Espanha). Professora Associada ao Programa de Pós-Graduação em Educação da Universidade Federal FluminenseFE/UFF (Niterói). E-mail: dv.terra@terra.com.br.
} 
em média 20 alunos por turma com idades entre 4 e 5 anos. A proposta de trabalho no primeiro bimestre desse ano era problematizar a temática corpo, pensando a imagem e consciência corporal desses sujeitos.

Contudo, ao começar as atividades na quadra, observamos que os alunos das turmas 51 e 52, procuravam pedras e pedaços de plantas de forma imediata para brincar. Entretanto, essa questão comprometeu o andamento das aulas e o desenvolvimento do trabalho, visto que os alunos acabavam ficando dispersos, dificultando a organização para e durante as atividades, bem como a disputa agressiva entre eles por esses objetos,causando conflitos percebidos no andamento das aulas.

Alguns até realizavam explorações com esses objetos como: jogar para cima, para o lado, chutar e jogar para o outro. As duas turmas possuem características como o comportamento agitado, o faz - de -conta e o egocentrismo. A partir desse contexto, surgiram reflexões como: Por que esses objetos chamam tanta atenção dessas crianças? Essas crianças reproduzem o que veem no seu cotidiano?, A estrutura da quadra de aula tem sido um espaço favorável nas aulas de educação física para a educação infantil?,A faixa etária em que esses alunos se encontram tem relação com a busca por esses objetos? Eles têm acesso apenas há esses tipos de objetos?.

A construção dos brinquedos surge no intuito de dialogar as características da turma e a problemática observada. Dessa forma, pensamos na seguinte pergunta: No cotidiano das aulas de educação física o brinquedo pode ser usado como conteúdo ou recurso pedagógico na Educação Infantil?

O artigo tem como objetivo compreender como as crianças se apropriam do brinquedo nas aulas de Educação Física na Educação Infantil a partir de estratégias pedagógicas utilizadas para problematização organizada pelo professor.

\section{PENSANDO NAS IMPLICAÇÕES NO USO DOS BRINQUEDOS}

A partir dessa pergunta inicial, instauramos um processo de busca de autores e documentos que discutem o brinquedo. Para Kishimoto (2008), a infância expressa no brinquedo contém o mundo real, com seus valores, modos de pensar e agir e o imaginário do criador do objeto. Pensar a infância seja na rua, na escola e nos mais variados ambientes é fundamental. Freire (1997), atenta em seus estudos à necessidade vivenciar a infância e suas implicações na vida da criança, pois na maioria das vezes encara-se a criança uma tábua rasa que não sabe de nada e que a partir do processo de escolarização irá aprender as ciências. 
Encontramos nos Referenciais Curriculares Nacionais para a Educação Infantil, itens que falam sobre o cuidar, o estímulo à brincadeira, ao movimento, ao imaginário, orientações didáticas, objetivos, conteúdos, a organização do espaço/tempo, seleção de conteúdos e os recursos materiais, onde:

Os brinquedos constituem-se, entre outros, em objetos privilegiados da educação das crianças. São objetos que dão suporte ao brincar e podem ser das mais diversas origens materiais, formas, texturas, tamanho e cor. Podem ser comprados ou fabricados pelos professores e pelas próprias crianças; podem também ter vida curta, quando inventados e confeccionados pelas crianças em determinada brincadeira e durar várias gerações, quando transmitidos de pai para filho. Nessa perspectiva, as instituições devem integrá-los ao acervo de materiais existentes nas salas, prevendo critérios de escolha, seleção e aquisição de acordo com a faixa etária atendida e os diferentes projetos desenvolvidos na instituição (RCNEI, 1998, p. 71).

Pensamos que todo brinquedo pela sua constituição traz sua identidade que o diferencia dos outros, bem como, as atribuições imaginárias e significativas que as crianças inserem no contato com esse objeto. Dessa forma, dialogar com a temática do brinquedo constituirá um processo que observação e múltiplos olhares.

Ratificamos a importância do olhar e o estabelecimento desses aspectos ao trabalharmos nas aulas de educação física escolar a temática do brinquedo na Educação Infantil. O estímulo à criatividade dos alunos é uma perspectiva crucial na construção dos brinquedos. Segundo Taffarel (1985), existem critérios que facilitam o desenvolvimento da criatividade como: o clima de liberdade, decisões em aberto com possibilidades de divergência, respeito aos pontos-de-vista individuais, criar canais de comunicação e não obstáculos, métodos de trabalho flexíveis, trabalho em pequenos grupos, para facilitar a comunicação entre os alunos e trabalhos com objetividade. Valorizar esse viés é dialogar com o outro, com a liberdade de criação e o contato com outras práticas pedagógicas.

No campo das relações, o trabalho com brinquedos permite uma discussão interessante, pois a construção coletiva exige estratégias que facilitem a organização do espaço, bem como trazer o que os alunos compreendem como brinquedo, a disposição dos alunos, o interesse da turma em construir e a relação criança/objeto/brinquedo, sua criação e como estabelece essa relação. Freire (1997), menciona a criança como um especialista em brinquedo, ou seja, possui essa característica de “dar vida” e criar a partir da sua imaginação. 
Concordamos com Varotto; Silva (2004), Junior; Tavares (2010), Freitas; Stigger (2015) ao incentivarem a reconstrução e construção de objetos para brincar nas aulas de educação física escolar, favorecendo uma variedade de ações criativas e simbólicas. Os brinquedos estão para além de meros recursos didáticos e acervos que devem ficar "guardados” nas salas de aula. Embarcar nessa pesquisa acerca dos brinquedos é um processo que exige metodologia, observação, reflexão, percepção e sensibilidade.

\section{QUEM FALA OU JÁ FALOU DO BRINQUEDO?}

Pela definição de Ferreira (1999), a palavra "brinquedo” seria: “um instrumento lúdico que auxilia na diversão”, “objeto que serve para criança brincar”, “entreter-se”, “divertir-se”. Uma tampinha de garrafa se torna uma bola, e ainda uma garrafa, um pino para jogar boliche a partir do sentido e significado, dado pelo sujeito que o chuta, arremessa, experimenta e o vive.

Diversos autores na Educação Física e Educação defendem o Jogo, Brinquedo e Brincadeira como pilares da infância, discutindo suas implicações nessa fase da vida humana. Dentre eles, destacamos: Benjamin (1984), Oliveira (1986), Oliveira (1989), Brougère (2004), Huizinga (2007), Kishimoto (2008) que problematizam o jogo e suas peculiaridades, o brincar em si, o faz- de- conta, a imaginação, as regras dos jogos/brincadeiras, seus sentidos e significados, a capacidade de mudálas/adaptá-las ao longo dos jogos, os tipos de brincadeiras e o brinquedo. Vamos nos ater, especificamente, aos autores que em suas produções apresentam reflexões sobre o brinquedo.

Segundo Kishimoto (2008), o brinquedo pode ser compreendido como objeto, suporte da brincadeira que supõe uma relação íntima com a criança e uma indeterminação quanto ao uso das regras. O faz de conta, o imaginário, possibilita à criança tornar-se o que quiser, seja um objeto, animal, um sentimento e utilizar o brinquedo da forma que lhe convém.

Além desse aspecto, destaca os tipos de brinquedos, pois o brinquedo educativo usado em situações lúdicas criadas pelo adulto pode favorecer a aprendizagem. Ou seja, a intenção dada pode favorecer qualitativamente o trabalho, visto que ao se ligar aos conhecimentos dos alunos potencializa sua ação no processo de ensino e aprendizagem. Apresenta uma dimensão lúdica e educativa. “A primeira está relacionada à diversão, prazer e até o desprazer. A educativa é caracterizada no sentido de que o brinquedo ensina qualquer coisa que complete o individuo em seu saber e conhecimentos” (KISHIMOTO, 2008, p. 35).

Gilles Brougère, em seu livro "Brinquedo e Cultura”, apresenta reflexões pertinentes que reforçam a relação de quanto o brinquedo exterioriza representações e é um produto da sociedade 
em que vivemos. Para esse autor, o brinquedo possui a característica de ser um objeto portador de significados rapidamente identificáveis, remetendo a elementos legíveis do real ou do imaginário da criança. Os brinquedos podem ser definidos por duas maneiras: pela brincadeira ou pela representação social, visto que:

No primeiro caso, o brinquedo é aquilo que é utilizado como suporte numa brincadeira; pode ser um objeto manufaturado, um objeto fabricado por aquele que brinca, uma sucata, efêmera, que só tenha valor para o tempo da brincadeira, um objeto adaptado. Tudo pode se tornar um brinquedo e o sentido de objeto lúdico só lhe é dado por aquele que brinca enquanto a brincadeira perdura. No segundo caso, o brinquedo é um objeto industrial ou artesanal, reconhecido como tal pelo consumidor em potencial, em função de traços intrínsecos (aspecto, função) e do lugar que lhe é destinado no sistema social de distribuição de objetos, ou seja, um projeto adulto destinado às crianças e que tais objetos são reconhecidos como propriedade da criança, oferecendo-lhe a possibilidade de usá-los conforme a sua vontade, no âmbito um controle adulto limitado (BROUGÈRE, 2004, p. 63).

É considerável a intensidade do processo de socialização entre o brinquedo e a criança nos dois sentidos apresentados pelo autor. Na medida em que são fabricados e pensados por adultos, os papéis sociais acabam sendo simbolizados nesses objetos. As imagens criadas, por exemplo, a relação materna com as bonecas ou os super- heróis que o devem proteger a todo custo.

Esses comportamentos vão sendo despertados na infância e sendo naturalizados ao longo do desenvolvimento da criança. Outro ponto crucial no trabalho de Brougère (2004) é sobre o papel do brinquedo na impregnação cultural da criança. Defende que não podemos considerar o brinquedo apenas pela sua dimensão funcional, mas pensar sua dimensão simbólica, principalmente pelo que pode representar para criança em um dado momento.

Não devemos pensar o brinquedo destacado de um contexto social. Logo, a problemática da influência da Indústria Cultural na cultura infantil é discutida por Oliveira (1986) que realiza uma análise de como as crianças são consumidoras desses artefatos e além de dissertar acerca da existência de uma cultura para a criança ou uma cultura da infância.

Esse outro olhar insere a perspectiva de que existem grandes/pequenos empresários que investem na produção de um material voltado para a infância, caracterizando o brinquedo como mercadoria. Os processos de produção e reprodução são destacados pelo autor ao longo do livro, representando em grande parte os investimentos de países dominantes em países dominados para a fabricação dos brinquedos. 
No capítulo IV, “o Brinquedo como Mensagem”, há destaques relevantes para a influência dos jornais, revistas, livros, músicas, filmes, programas de rádio e televisão. O brinquedo também passa a ser uma mercadoria cultural nesse sentido, adquirindo um sentido que transplanta os valores na indústria capitalista como os processos de terceirização da produção e a exploração de mão de obra barata das classes mais baixas para construção (OLIVEIRA, 1986).

Interessante pensar na evolução da sociedade que se insere no desenvolvimento desses objetos destinados em sua maioria para as crianças. Benjamin (1984) destaca que nos primórdios, os brinquedos não eram inventados por fabricantes especializados, mas que nasceram de oficinas de entalhadores de madeira, fundidores de estanho. Ratifica que a função de fabricar os brinquedos não era de um único tipo de indústria. A divisão dos processos era causada pela diferença dos materiais usados, o que acabava encarecendo a mercadoria.

Para Oliveira (1989, p. 29), “a identidade do autor, por exemplo, que se exprimia na obra realizada como marca singular e intransferível, conformou-se ao reconhecimento de um certo estilo ou nem mesmo isso”. Esse contexto está situado pela relação do brinquedo artesanal e industrial. O processo de artificialização do brinquedo fomentou a substituição de elementos da natureza usados para fazer o brinquedo utilizando plástico.

Percebemos que o brinquedo é reflexo de diversificados contextos em nossa sociedade e que desconstruí-lo e reconstruí-lo favorece o reconhecimento de outros processos culturais, econômicos e sociais. Inverter a lógica de cima para baixo em sua construção é o movimento que defendemos nesse trabalho, visto que a criança pode e deve construir seu próprio brinquedo.

Os autores citados contribuem para termos uma fundamentação acerca dos brinquedos, seu significado, dimensões e suas implicações no contexto cultural e social. Nesse sentido, avançamos com a intenção de discutir e descrever o processo de intervenção na perspectiva da construção dos brinquedos.

\section{A CONSTRUÇÃO DOS BRINQUEDOS NAS AULAS DE EDUCAÇÃO FÍSICA NA ESCOLA MUNICIPAL CORA CORALINA}

A partir das reflexões deste artigo, caminhamos no sentido de apresentar a experiência no que tange o processo de construção dos brinquedos e vivencia dos alunos. Optamos por inserir imagens no texto, tecendo comentários acerca da realização, desdobramentos e significados captados ao longo das aulas. 
Elegemos a observação participante como instrumento de coleta de dados. Em Gil (2002), a observação participante se encerra na participação real do conhecimento na vida da comunidade, do grupo ou de uma situação determinada. Nesse caso, o observador assume, pelo menos até certo ponto, o papel de um membro do grupo.

Antes de começarmos efetivamente a construção dos brinquedos, realizamos um diagnóstico nas turmas, através de desenhos para perceber quais eram os referenciais de brinquedos e o que as crianças entendiam como brinquedo.

Nessa aula, o objetivo foi identificar o que os alunos das turmas 51 e 52 compreendiam como brinquedo. Segundo Smolka (2009, p.106), “desenhar é um tipo predominante de criação na primeira infância, pois enquanto desenha a criança pensa no objeto que está representando, como se estivesse falando dele” .

\section{Figura1. Desenhando brinquedos}

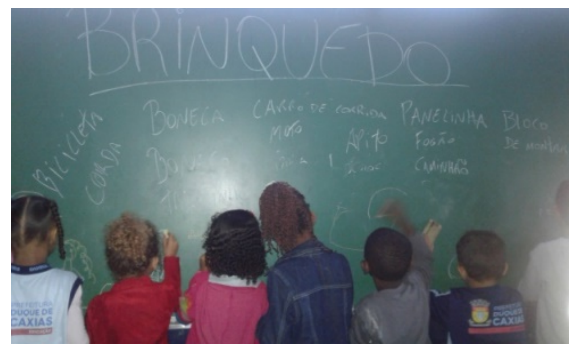

Fonte: Próprio autor, 2018.

\section{Figura 2. Meu pai}

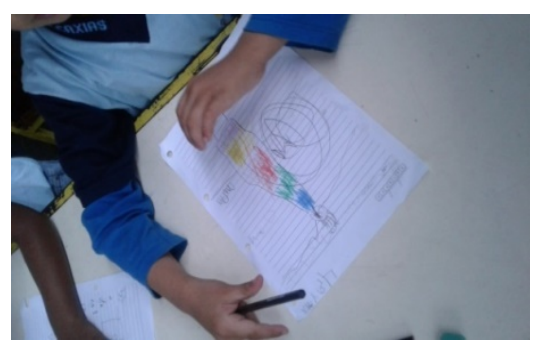

Fonte: Próprio autor, 2018.

Na figura 1, a palavra brinquedo inspirou os alunos a desenharem também no quadro imediatamente após a escrita do professor. A intenção foi contextualizar e criar um ambiente brincante. Na figura 2, percebemos que muitos alunos compreendem os familiares como brinquedo. Os alunos verbalizaram sobre este aspecto. “Tio, eu desenhei meu pai [...] eu brinco muito com ele”. Essa relação pode ser pensada a partir do viés da imaginação, sendo uma categoria de análise e uma característica fundamental inserida nas discussões de Brougère (2004), Huizinga (2007) e Kishimoto (2008) para pensar a infância.

Ainda nesse contexto, outros desenhos foram confeccionados pelos alunos como podemos observar nas imagens a seguir: 


\section{Figura 3. Desenho coletivo}



Fonte: Próprio autor, 2018.

\section{Figura 4. Boneco}

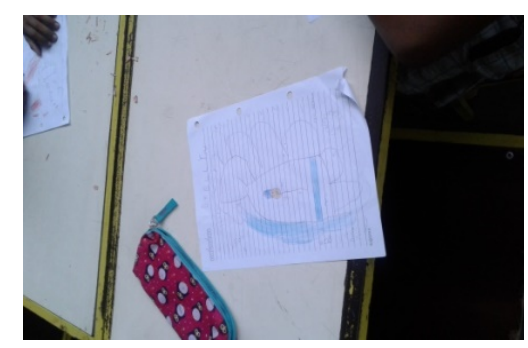

Fonte: Próprio autor, 2018.

Outros desenhos foram confeccionados pelos alunos como podemos observar nas imagens acima. Nas figuras 3 e 4, podemos perceber que o desenho coletivo foi uma das características identificadas nas turmas. A figura 4, representa um boneco que ratifica como determinados brinquedos fazem parte da realidade e o cotidiano dessas crianças.

Após esse diagnóstico, estabelecemos que seria interessante trazer para os alunos brinquedos que eles não conheciam ou não tivessem ideia que poderiam ser construídos. Durante o mês de agosto, aplicamos a proposta nas turmas 51 e 52. Construímos cerca de 5brinquedos dentre eles: Bola de jornal, Garrafabol, Avião de jornal, Rabo do foguete, Peteca.

A bola de jornal foi o primeiro brinquedo construído com as turmas. Foram separados folhas de jornais e rolos de barbante. Cada aluno recebeu duas ou três folhas e um pedaço de barbante para amarrar a bola. A opção de construir em sala se deu pela questão do calor e da quadra de aula ser aberta, ficando coberta totalmente pelo sol no horário das aulas com essas turmas.

\section{Figura 5. Bola de Jornal}

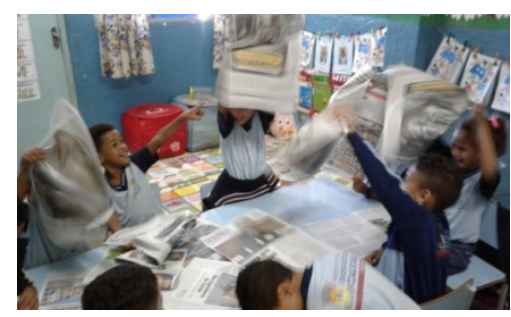

Fonte: próprio autor, 2018.

\section{Figura 6. Bola de Jornal}

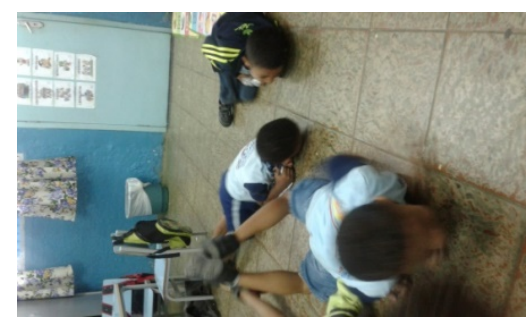

Fonte: próprio autor, 2018.

Na figura 5, os alunos tinham acabado de receber a folha de jornal e já estavam manipulando. A verbalização dos alunos voltou - se para o fato dos mesmos imaginarem que o jornal pudesse ser um “cobertor”. Dialogando com Brougère (2004), entendemos que o aspecto material do brinquedo sendo um fator preliminar à própria significação fez-se presente nesse 
sentido, visto que para esse autor se o brinquedo tem um determinado significado é porque ele é dotado de uma determinada forma.

Figura 7. Bola de Jornal

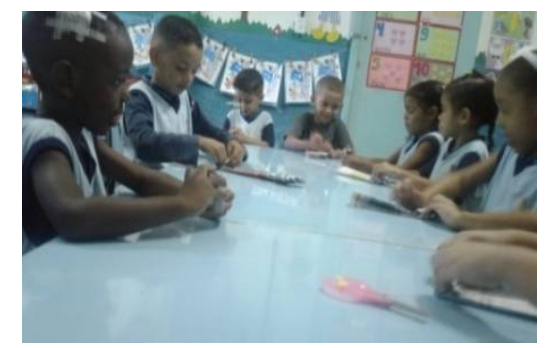

Fonte: próprio autor, 2018.

\section{Figura 8. Bola de Jornal}

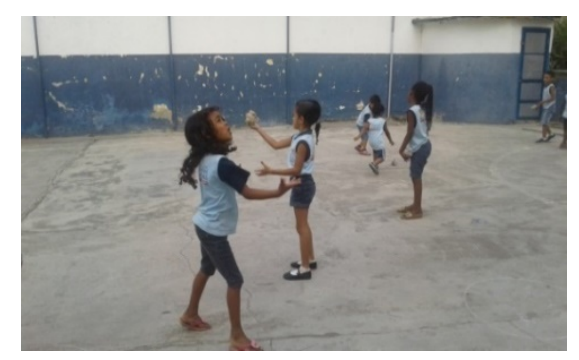

Fonte: próprio autor, 2018.

Na turma 52, a figura 7 nos remete há um contexto em que os alunos demonstraram falas do tipo: “Tio, não consigo amassar o jornal”, outros disseram que "nunca tinham amassado jornal” e, além disso, precisaram de ajuda para terminar o brinquedo. Consideramos que esses estímulos realizados devem fazer parte da progressão pedagógica ao se construir os brinquedos, principalmente por favorecer novas experimentações as crianças.

Na figura 8, fundamentamos a partir de Brougère (2004), que situa a manipulação dos brinquedos permite manipular os códigos culturais, sociais e projetar ou exprimir, por meio do comportamento. Corroborando com esse contexto Kishimoto (2008), fala que o brinquedo surge como um pedaço da cultura colocado ao alcance da criança como um parceiro, bem como sua manipulação que leva a criança a ação, representação, o agir e a imaginação.

Essas contribuições nos ajudam a compreender a importância do brinquedo no contexto pedagógico, sendo revelado através das brincadeiras e interações exteriorizadas pelas crianças ao longo das aulas. O segundo brinquedo construído foi o rabo do foguete. Essa denominação foi apresentada pelos alunos da turma 51, visto que ao manipulá-lo perceberam que podiam jogar para cima parecendo um foguete.

\section{Figura 9. Rabo do foguete}



Fonte: próprio autor, 2018.

\section{Figura 10. Rabo do foguete}

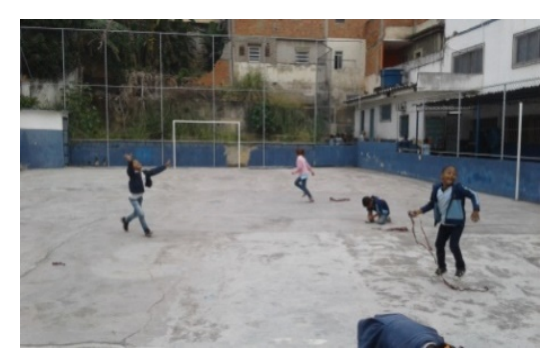

Fonte: próprio autor, 2018. 
Para construir esse brinquedo, o processo de ensino foi organizado da seguinte forma: Foram distribuídas duas folhas jornal partidas ao meio para cada aluno, fitas de papel crepom e um pedaço de barbante. Começamos dobrando o jornal, a fim de fazer um "bombom” de jornal, denominação verbalizada pelos alunos. A intervenção se deu no intuito de explicar que o jornal deveria envolver o papel crepom para segurar e para finalizar usar o barbante para amarrar.

A movimentação dos alunos na quadra pode ser destacada, principalmente pela sua relaçãocom a exploração do brinquedo. Vygotsky (1984) enfatiza a ação e o significado do brincar no sentido de que a criança não enxerga o objeto como ele é, ou seja, lhe confere um novo significado. Muitos giravam o rabo do foguete, jogavam para cima, outros arremessavam para longe e buscavam, enrolavam no corpo, colocavam no chão e pulavam. Esse fato também foi percebido na turma 52, como observaremos nas imagens à seguir:

Figura 11. Rabo do Foguete

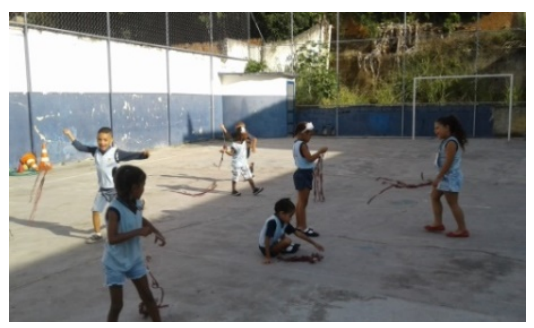

Fonte: próprio autor, 2018.

\section{Figura 12. Rabo do Foguete}

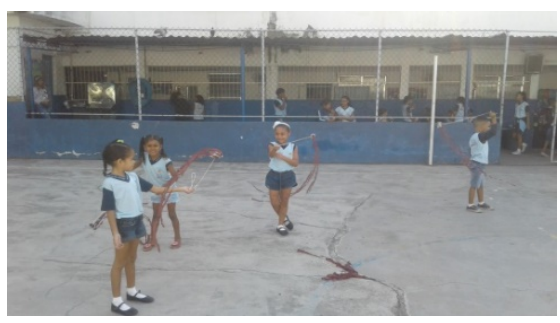

Fonte: próprio autor, 2018.

Para Oliveira (1989), os brinquedos industrializados são criados com o objetivo de inserir nas crianças formas de agir e pensar calcados na classe dominante, limitando os sentidos e significados que esses sujeitos poderiam criar com esses objetos. Fica evidente que essa intervenção incentivou a exploração em uma perspectiva criativa, reinventando as formas de manipulação e vivência do brinquedo.

O terceiro brinquedo foi a peteca de jornal. O processo de construção foi organizado com os alunos pegando duas ou mais folhas de jornal, visto que foram amassando até virar uma bola consistente. Após esse primeiro momento, foi distribuída mais uma folha para cobrir e dar forma ao brinquedo. 


\section{Figura 13. Peteca de Jornal}

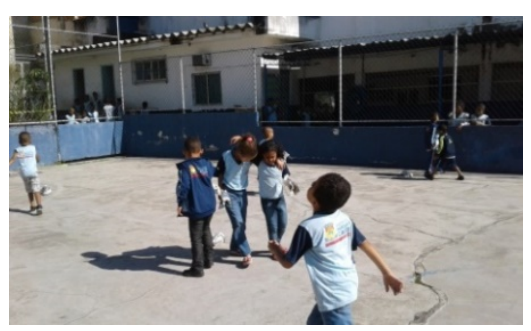

Fonte: próprio autor.
Figura 14. Peteca de Jornal

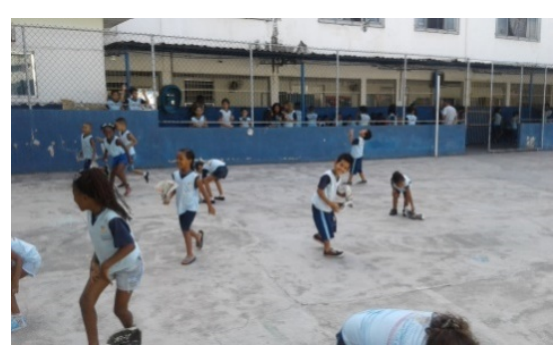

Fonte: próprio autor.

Durante o processo de construção os alunos colocaram outro nome no brinquedo. As duas turmas associaram com o “ovo de páscoa”. Pensando com Brougère (2004), o conceito de representação nos diz que "manipular brinquedos remete, entre outras coisas, a manipular significações culturais originadas numa determinada sociedade” (p. 43). Logo, o sentido dado pelos alunos a partir do contato com esse brinquedo, reafirma a atribuição ao significado e a representação que esse brinquedo gerou para eles naquele momento.

Em Piaget (2007), temos as etapas do desenvolvimento humano. No estágio pré- operatório umas das suas características é a dimensão simbólica. A criança nesse período manifesta a linguagem, dando um salto no contexto do seu desenvolvimento. Esse aspecto pode ser observado através de sua verbalização e ação.

Na figura 13, a afetividade manifestada pelos alunos ao longo das atividades foi observada. Encontramos trabalhos no campo da educação física nas aulas de educação infantil que discutem essa questão como: Nicoletti et al. (2013), Vieira; Alves; Rodrigues (2013) e Palma; Conti (2016). Essas produções destacam a importância e o olhar para a questão afetiva manifestada pelos alunos, no que tange as emoções, sentimentos bem como ser uma fonte de pesquisa não só na Educação Infantil, mas em todas as etapas da educação básica.

O quarto brinquedo construído foi o Garrafabol. A construção se deu a partir da formação de uma bola de jornal com mais ou menos duas folhas e uma garrafa pet cortada ao meio, visto que aproveitamos a parte de cima da garrafa com tampa. Optamos por levar tesouras sem ponta e explicar aos alunos o processo de corte da garrafa. 


\section{Figura 14. Garrafabol}

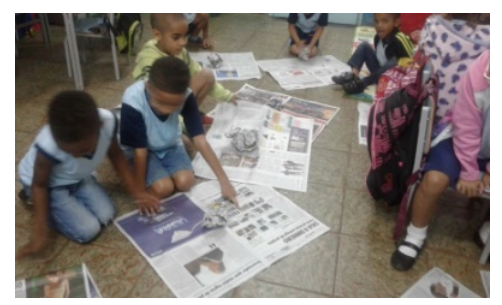

Fonte: próprio autor, 2018.

\section{Figura 15. Garrafabol}



Fonte: próprio autor, 2018.

Na figura 14, podemos observar o brinquedo sendo construído pelos alunos. Nesse dia, a quadra estava molhada o que não possibilitou a vivência neste espaço, porém realizamos em sala. Dessa forma, trazemos uma discussão relacionada ao fazer o brinquedo, pois:

Através do objeto lúdico que constrói, o artesão anônimo de brinquedo se transforma em produtor de cultura. Acrescenta a ele o caráter lúdico, a alegria e o encantamento. Prescinde até mesmo do dinheiro, ponto principal que rege as relações econômicas, sociais e culturais na sociedade capitalista. Nega-se a se curvar ante as determinações e, além de tudo, ainda se diverte muito com isso (OLIVEIRA 1989, p.25).

Esse pensamento corrobora com o sentido e significado da construção desses brinquedos no contexto apresentado. Cada aluno constrói sua bola de maneira diferente, dando um toque diversificado e pessoal, pois os mesmos tiveram as opções de construir uma bola maior ou menor, de usar o barbante ou fita adesiva para envolvê-la. Reinventa e rompe com os padrões de uma sociedade que insere valores e normas nesses objetos.

Na figura 15, a discussão volta-se para a observação do corpo no espaço. A partir de Mattos e Neira(2003), percebemos que o movimento é o meio de expressão fundamental das crianças na Educação Infantil, visto que todos os educadores devem compreender esse movimento muito além do olhar biológico ou fisiológico, pois o corpo que corre e cresce é o mesmo que sente, conhece e se expressa. Logo, compreender e olhar o corpo sob a ótica da sua totalidade corresponderá há uma educação que está para além da fragmentação e dicotomia.

O último brinquedo construído foi o Avião de jornal. Esse brinquedo foi considerado pelos alunos como o mais fácil de ser construído. Sua constituição se dá através de dobraduras que vão dando forma ao avião. Primeiro dobramos a folha ao meio, cobrindo o outro lado, depois abrimos nosso "livro" e fazemos uma “orelha”. Após, dobramos para formar a asa e dar o acabamento ao brinquedo. 
Figura 16. Avião de Jornal

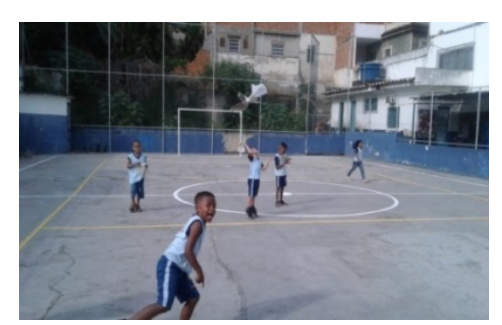

Fonte: próprio autor, 2018.

\section{Figura 17. Avião de Jornal}

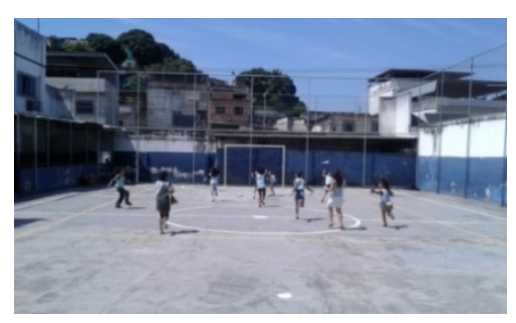

Fonte: próprio autor, 2018.

Na figura 16 e 17, está representado um momento de exploração livre por parte dos alunos como foi realizado em todas as aulas. Essas imagens colocam na roda a discussão de como a brincadeira está inserida no cotidiano de escolares da Educação Infantil. O direcionamento dado pelos alunos com esse material foi sentido de jogar para diversas direções, correr pela quadra manuseando o brinquedo e imitar com o corpo um avião.

A brincadeira a partir de reflexões Kishimoto (2008), traz um sentido fundamental para o desenvolvimento da identidade e da autonomia. Desde muito cedo as crianças se comunicam por gestos, sons e mais tarde a imaginação. Podemos dizer que brincar é uma necessária para sua formação. Logo, a partir dessa linguagem a criança se comunica e se expressa de diversas formas como podemos observar nas imagens, seja imitando o brinquedo construído ou usando o avião como um automóvel.

O faz de conta sempre esteve presente nas aulas com as turmas 51/ 52. Isso é constatado a partir da verbalização dos alunos nessa aula a partir de falas como: “Tio, olha como posso voar”, “Tio, eu sou um avião”, “Tio, primeira vez que ando de avião”,“Tio, meus braços parecem asas”. Essa perspectiva vai de encontro aos papéis sociais que a brincadeira pode levar através do contexto da vida diária dos alunos, bem como perceber que o faz - de - conta contribui para o desenvolvimento infantil, pois a criança ao imaginar transfere-se para diversificados imaginários sociais.

\section{CONSIDERAÇÕES FINAIS}

A partir das problematizações apresentadas na experiência descrita, estabelecemos discussões que perpassaram pelos referenciais consultados e nas descrições realizadas. Nesse sentido, refletimos e dialogamos sobre o ponto de vista de autores da Educação e Educação Física no que tange o brinquedo e o processo de intervenção na prática pedagógica exemplificada. 
Com a observação participante, a inserção do professor facilitou e impulsionou o diálogo com a temática, bem como com os sujeitos escolares das turmas 51 e 52 da E. M. Cora Coralina. Ratificamos que a escolha pelos materiais como jornal, barbante, papel crepom e garrafa pet, foi pensada a partir da faixa etária (4 a 5 anos) em que os alunos se encontram.

Estabelecemos como objetivo desse trabalho, compreender como as crianças se apropriam do brinquedo nas aulas de Educação Física na Educação Infantil a partir de estratégias pedagógicas utilizadas para problematização organizada pelo professor.

Nesse sentido, percebemos que ao longo do processo categorias como a imaginação, a imitação, o simbólico, a representação, o faz- de conta e reinvenção do brincar surgiram de maneira recorrente nas aulas. Essas categorias nos ajudam a compreender que os alunos se apropriaram dos brinquedos através do uso da imaginação, demonstrando suas representações a partir do seu cotidiano bem como, o faz de conta como característica das turmas e a capacidade de reinventar o brinquedo e o brincar.

Consideramos que a construção como estratégia pedagógica melhorou o relacionamento dos alunos durante aulas, estimulou a afetividade, a socialização, os conflitos exacerbados e ainda despertou variadas emoções, expressões e sensações. Frente a essa experiência e as resposta significativas das crianças e agora compreendendo o potencial do brinquedo no desenvolvimento dos alunos/as perguntamos: O brinquedo tem sido usado como conteúdo ou recurso pedagógico para as aulas de Educação Física na Educação Infantil?

A partir das reflexões apresentadas neste trabalho, entendemos que o brinquedo foi utilizado como conteúdo das aulas de educação física, visto que a descrição do processo demonstrou que o uso está para além do seu sentido utilitário. Não construímos para vivenciar, mas construímos vivenciando. Essa prerrogativa está para além do fazer por fazer, ou mera prática. Foi na construção coletiva que trabalhamos valores, o movimento, a compreensão do espaço do outro, a criatividade, o brincar e a corporeidade. 


\section{REFERÊNCIAS}

BARBOSA, M.C.S. Por amor e por força: Rotinas na educação infantil. Porto Alegre: Artmed, 2008. 240p.

BRASIL. Lei de diretrizes e B. Lei n ${ }^{\circ}$ 9.394/96, de 20 de dezembro de 1996. 312p.

Ministério da Educação e do Desporto. Secretaria de Educação Fundamental. Referencial curricular nacional para a educação infantil / Ministério da Educação e do Desporto, Secretaria de Educação Fundamental. Brasília: MEC/SEF, 1998. 101p.

BENJAMIN, W. Reflexões: a criança, o brinquedo, a educação. São Paulo: Summus, 1984. 117p.

BROUGÈRE, G. Brinquedo e Cultura. 5. ed, São Paulo: Cortez, 2004.110p.

CERTEAU, M. de. A invenção do cotidiano: 1. ed. Petrópolis: Vozes, 2005. 372p.

FERREIRA, A.B de H. Novo Aurélio Século XXI: dicionário da língua portuguesa. Rio de Janeiro: Nova Fronteira, 1999. 2128p.

FREIRE, J. B. Educação de corpo inteiro: teoria e prática da educação física. São Paulo: Scipione, 1997. 290p.

FREITAS, M. V; STIGGER, M. P. As brincadeiras nas aulas de educação física e seus significados para as crianças. Motrivivência, Florianópolis, v. 27, n. 45, p. 74-83, 2015. Disponível em: <https://periodicos.ufsc.br/index.php/ motrivivencia/article/view/2175-8042.2015v27n45p74>. Acesso em: 23 jun. 2017.

HUIZINGA, J. Homoludens: o jogo como elemento da cultura. 5. ed. São Paulo: Perspectiva, 2007. 243p.

JUNIOR, M, S; TAVARES, M. Jogo, brinquedo e Brincadeira nas aulas de Educação Física. Efedeportes, Buenos Aires, v. 15, n. 144, p. 1, 2010. Disponível em: <http://efdeportes.com/efd144/jogo-brinquedo-e-brincadeira-emeducacao-fisica.htm>. Acesso em: 23 jun. 2017.

KISHIMOTO, T. M. (Org.). O jogo e a educação infantil. In: Jogo, brincadeira e a educação. 1. ed. São Paulo: Cortez, 2008. 183p.

MATTOS, M. G.; NEIRA, M. G. Educação física infantil: construindo o movimento na escola. 4. ed. Guarulhos: Phorte, 2003.

NICOLETTI, L.P; GOMES, V.L.F. D; ROZALES, F.T.H; CARRASCO, A.D; BRAGA,M. DE N. Educação Infantil, Educação Física e afetividade. Efedeportes, Buenos Aires, v. 18, n. 184, p. 1-1, 2013. Disponível em: <http://www.efdeportes.com/efd184/educacao-infantil-educacao-fisica-e-afetividade.htm>. Acesso em: 23 jun. 2017.

OLIVEIRA, P.de S. O que é Brinquedo? 2. ed. São Paulo: Brasiliense, 1989. 74p.

Brinquedo e Indústria Cultural. Rio de Janeiro, 1986. 96p.

PALMA, A. P.T. V; CONTI, L.C. F DE. Educação física na escola e a afetividade a construção do autorespeito. Educação, Santa Maria, v. 41, n. 1, p. 237-250, 2016.

PIAGET, J. Epistemologia Genética. Trad.: Álvaro Cabral. 3. ed. Martins Fontes: São Paulo, 2007. 123p.

SMOLKA, A. L. B. A Imaginação e Criação na Infância: ensaio psicológico. São Paulo: Ática, 2009. 135p.

TAFFAREL, C.N.Z. Criatividade nas aulas de Educação Física. Rio de Janeiro: Ao Livro Técnico, 1985. 96p.

VAROTTO, A, M;SILVA, M, R. DA. Brinquedo e indústria cultural: sentidos e significados atribuídos pelas crianças. Motrivivência, Florianópolis, v. 4, n. 23, p. 169-190, 2004. Disponível em: <https://periodicos.ufsc.br/index.php/ motrivivencia/article/view/2034/3906>. Acesso em: 23 jun. 2017.

VIEIRA, M. B; RODRIGUES, L.A. R; ALVES, E.M. A. DE FREITAS. A influência no desenvolvimento sócio-afetivo na aprendizagem de escolares na Educação Física Infantil. Efedeportes, Buenos Aires, v. 18, n. 182, p. 1, 2013.

VYGOTSKY, L. S. A Formação Social da Mente. São Paulo: Martins Fontes, 1984. 191p. 


\section{RESUMO}

Este trabalho parte do cotidiano da educação infantil de uma escola do Município de Duque de Caxias, localizada no Bairro de Gramacho. Discute um cenário despertado por alunos das turmas 51 e 52 da Educação Infantil durante as aulas de educação física escolar. Elegemos a observação participante como instrumento de coleta de dados. Tem como base teórica Michel Certeau, Tizuko Morchida Kishimoto, Gilles Brougère, Walter Benjamin, Paulo de Salles Oliveira, J ohan Huizinga que nos orientaram nas reflexões, discussões acerca das ações apresentadas pelos alunos que se apropriaram desse objeto nas aulas, gerando categorias como a imaginação, a imitação, representação e reinvenção do brincar, pois o processo de (re) construção materializou diversos conteúdos dialogados no cotidiano das aulas.

Palavras-chave: Cotidiano. Educação Física. Brinquedo.

\section{ABSTRACT}

This work is part of the daily life of early childhood education at a school in the municipality of Duque de Caxias, located in the neighborhood of Gramacho. Discusses a scenario sparked by students of 51 and 52 classes of early childhood education for the school physical education classes. We elect the participant observation as a data collection instrument. Has as theoretical basis Michel Certeau, Morchida Kishimoto, Gilles Tizuko Brougère, Walter Benjamin, Paulo de Salles Oliveira, Johan Huizinga who guided us in reflections, discussions about the actions submitted by students who have appropriated this object in class, creating categories like imagination, imitation, representation, and reinvention of the play, because the process of (re) construction materialized several everyday dialogados content of classes.

Keywords: Dailylife. Physical Education. Toy.

\section{RESUMEN}

Este trabajoes parte de la vida cotidiana de laeducaciónpreescolaren una escuelaenelmunicipio de Duque de Caxias, ubicadoenelbarrio de Gramacho. Habla de una situación provocada por losestudiantes de clases 51 y 52 de educación infantil para lasclases de educación física de laescuela. Elegimoslaobservación participante como uninstrumento de recogida de datos. Tiene como base teórica Michel Certeau, MorchidaKishimoto, Gilles TizukoBrougère, Walter Benjamin, Paulo de Salles Oliveira, Johan Huizinga que nos guióenlas reflexiones, discusiones sobre lasacciones presentadas por losestudiantes que se hanapropiado de este objeto enclase, creandocategorías como imaginación, imitación, representación y reinvención de la obra, porque elproceso de (re) construcciónhabía materializado variosdiarios dialogados de contenido de lasclases.

Palabras clave: Vida cotidiana. Educación física. Juguete. 